\title{
Ring-shaped thrombus in left atrial appendage: a contraindication for valvotomy
}

Himanshu Mahla, Prabhavathi Bhat, Shivakumar Bhairappa, Cholenahally Nanjappa Manjunath

Department of Cardiology, Sri Jayadeva Institute of Cardiovascular Sciences \& Research, Bangalore, Karnataka, India

\section{Correspondence to}

Dr Shivakumar Bhairappa, snbhairappa@gmail.com
To cite: Mahla $\mathrm{H}$, Bhat $\mathrm{P}$, Bhairappa S, et al. BMJ Case Rep Published online: [please include Day Month Year] doi:10.1136/bcr-2013201108

\section{DESCRIPTION}

45-year-old woman presented with rheumatic heart disease-severe mitral stenosis. The patient had atrial fibrillation with New York Heart Association class II status. She was on diuretics, rate controlling drugs and warfarin $2 \mathrm{mg} /$ day. International normalised ratio (INR) value was 1.8. Transthoracic echocardiogram revealed no evidence of thrombus in left atrium or appendage. As valve morphology was suitable for valvotomy, warfarin was stopped 5 days before planned date of valvotomy and injectable heparin started. Transesophageal echocardiogram was performed 3 days before planned valvotomy to rule out any thrombus. It revealed grade $4+$ spontaneous echocontrast (intense echodensity with very slow swirling movements of blood within left atrium and equal density in appendage) with ringshaped thrombus in left atrial appendage (figures 1 and 2; videos 1, 2, 3). Thrombus was echodense in periphery and echolucent in centre. This

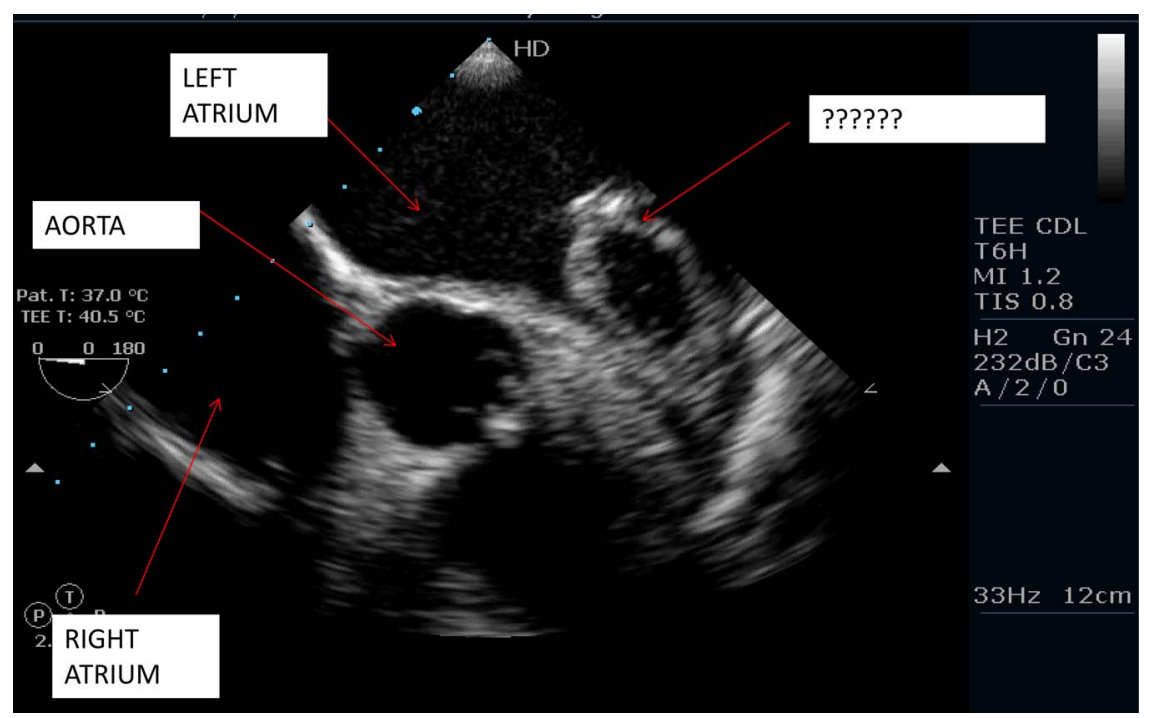

Figure 1 Tranesophageal echocardiogram showing ring-shaped fresh thrombus in left atrial appendage in $0^{\circ}$ view.

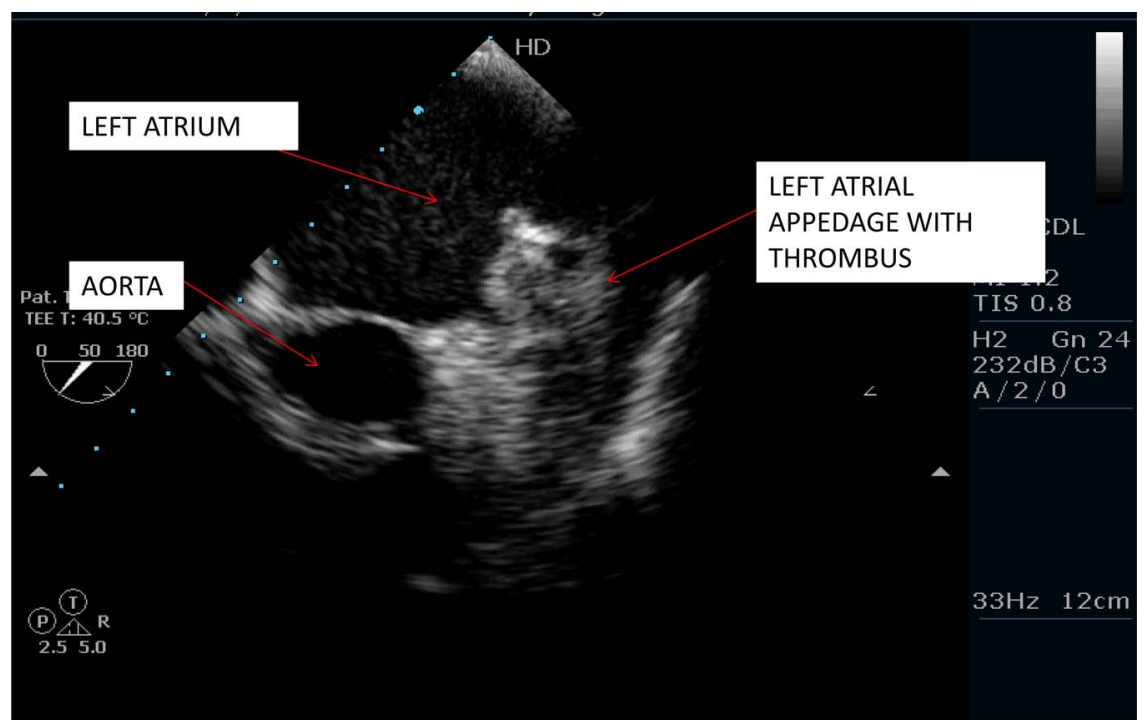

Figure 2 Transesophageal echocardiogram showing ring-shaped left atrial appendage thrombus in $50^{\circ}$ view. 


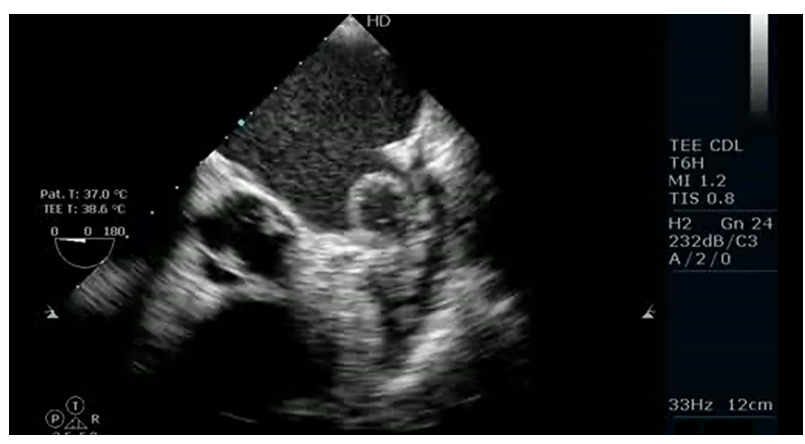

Video 1 Transesophageal echocardiogram showing grade 4+ SEC (intense echogenicity with slow swirling movement of blood) in left atrium with ring shaped clot in appendage extending to mouth of appendage in 0 degree view.

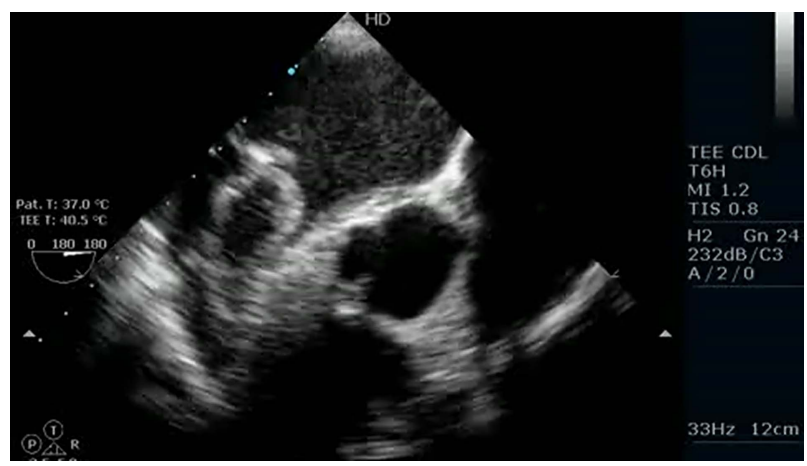

Video 2 Transesophageal echocardiogram showing showing grade 4 + SEC(intense echogenicity with slow swirling movement of blood) in left atrium with ring shaped clot in appendage extending to mouth of appendage in 180 degree view.

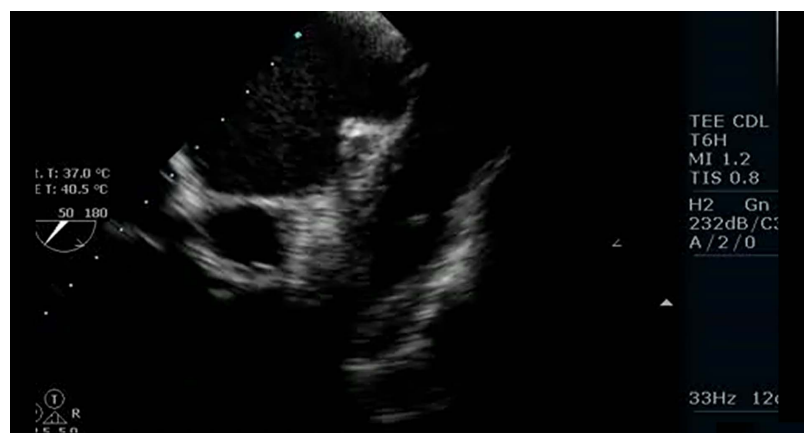

Video 3 Transesophageal echocardiogram showing showing grade 4 + SEC(intense echogenicity with slow swirling movement of blood) in left atrium with ring shaped clot in.

echocardiographic appearance of thrombus was suggestive of recent formation. Fresh thrombus have high chances of embolisation. Balloon mitral valvotomy was deferred. The patient discharged on anticoagulants (warfarin $3 \mathrm{mg} /$ day) with INR value of 2.7 .

Spontaneous echocontrast (SEC) ${ }^{1}$ in left atrium and appendage has been associated with high risk of embolisation but still balloon valvotomy can be performed, provided no thrombus formation is there. Our patient had fresh thrombus in left atrial appendage which was contraindication for valvotomy. Various studies support our decision. Even presence of SEC in left atrium with normal sinus rhythm ${ }^{2}$ has been associated with increased risk of thromboembolic stroke. Left atrial appendage velocity and $\operatorname{size}^{2}{ }^{3}$ has also been associated with increased risk of thromboembolic stroke but lesser compared with the presence of SEC. The presence of thrombus in left atrial appendage is an absolute contraindication for valvotomy.

Our case shows classical example of fresh thrombus in left atrial appendage in patient of rheumatic mitral stenosis with peculiar ring-shaped appearance of thrombus. Adequate anticoagulation followed by valvotomy is the usual approach for such cases in our institute.

\section{Learning points}

The presence of spontaneous echocontrast (echodensity with slow-swirling movement of blood) in left atrium or left atrial appendage is high-risk marker for thromboembolic complications during balloon mitral valvotomy.

- The presence of thrombus in left atrium or appendage is contraindication for balloon mitral valvotomy and an alarming indication for aggressive rate control and anticoagulation.

- Even in sinus rhythm, patients with spontaneous echocontrast in left atrium or appendage are at high risk for embolic events during long term.

Contributors HM performed echocardiography. HM, SB and PB prepared the article and CNM finalised the manuscript.

Competing interests None.

Patient consent Obtained.

Provenance and peer review Not commissioned; externally peer reviewed.

\section{REFERENCES}

1 Fatkin D, Kelly RP, Feneley MP. Relationship between left atrial appendage bllod flow velocity, spontaneous echocardiographic contrast \& thromboembolic risk in vivo. J Am Coll Cardiol 1994;23:961-9.

2 Sadanandan S, Sherrid MV. Clinical and echocardiographic characteristics of left atrial spontaneous echo contrast in sinus rhythm. J Am Coll Cardiol 2000;35:1932-8.

3 Bernhardt $\mathrm{P}, \mathrm{Schmidt} \mathrm{H}$, Hammerstingl $\mathrm{C}$, et al. Patients with atrial fibrillation and dense spontaneous echo contrast at high risk a prospective and serial follow-up over 12 months with transesophageal echocardiography and cerebral magnetic resonance imaging. J Am Coll Cardiol 2005;45:1807-12. 
Copyright 2013 BMJ Publishing Group. All rights reserved. For permission to reuse any of this content visit http://group.bmj.com/group/rights-licensing/permissions.

BMJ Case Report Fellows may re-use this article for personal use and teaching without any further permission.

Become a Fellow of BMJ Case Reports today and you can:

- Submit as many cases as you like

- Enjoy fast sympathetic peer review and rapid publication of accepted articles

- Access all the published articles

- Re-use any of the published material for personal use and teaching without further permission

For information on Institutional Fellowships contact consortiasales@bmjgroup.com

Visit casereports.bmj.com for more articles like this and to become a Fellow 